\title{
Exclusiones del espacio público de los habitantes de la calle en la ciudad de Buenos Aires
}

Public Space Exclusions of Street Dwellers in the City of Buenos Aires

Exclusões do espaço público dos moradores de rua na cidade de Buenos Aires

\section{Paula Cecilia Rosa*}

Recibido: 2 de mayo de 2017

Aprobado: 13 de diciembre de 2017

Doi: http://dx.doi.org/10.12804/revistas.urosario.edu.co/territorios/a.5632

Para citar este artículo:

Rosa, P. C. (2018). Exclusiones del espacio público de los habitantes de la calle en la ciudad de Buenos Aires. Territorios (39), 157-173. Doi: http://dx.doi.org/10.12804/revistas.urosario.edu.co/territorios/a.5632
* Licenciada en Sociología, Universidad de Buenos Aires. Doctora en Ciencias Sociales (ides - Universidad Nacional de General de Sarmiento). Investigadora Adjunta Conicet, Centro de Estudios Urbanos y Regionales CEUR/Conicet. Correo electrónico: paula_rosa00@yahoo.com. ar. ORCID: https://orcid. org/0000-0002-7529-5232 
Palabras clave

Ciudad, neoliberalismo, espacio público, habitantes de la calle.

Keywords

City, neoliberalism, public space, street dwellers.

Palavras-chave

Cidade, neoliberalismo, espaço público, moradores de rua.

\section{territarias 39} 158

\section{RESUMEN}

Este artículo pretende adentrarse en algunas de las posibles consecuencias que trae aparejada la implementación de políticas de tipo neoliberal en el espacio público, específicamente, en la Ciudad de Buenos Aires. El artículo se centra en la caracterización de la noción de 'ciudad neoliberal', para posteriormente adentrarse en las formas que asume la espacialidad neoliberal en dicha ciudad desde el caso de los habitantes de la calle, es decir, personas y familias que residen cotidianamente en el espacio público. Para desarrollar lo pretendido, el artículo versará en las formas por las cuales esta población se ve expulsada del espacio público por acciones indirectas y directas por parte de la administración de la ciudad. Asimismo, pretende dar a conocer una tendencia novedosa, en esta misma dirección, pero llevada a cabo por otro actor. Se hace referencia a la modalidad por la cual una parte de la ciudadanía asume, por sus propios medios, el reordenamiento del espacio urbano por medio de la instalación de barreras físicas para evitar u obstaculizar la presencia de esta población en los alrededores de sus propiedades. Este accionar permitiría observar la situación que atraviesan ciertos grupos sociales en una ciudad cada vez excluyente.

\section{AbSTRACT}

This article intends to delve into some of the possible consequences that the implementation of neoliberal policies entails in the public space, specifically, in the City of Buenos Aires. The article focuses on the characterization of the notion of neoliberal city, to later enter into the forms that neoliberal spatiality assumes in that city through the case of the street dwellers, that is, people and families that reside daily in the public space. To develop what is intended, the article will deal with the ways in which this population is expelled from the public space by indirect actions as directed by the city administration. Likewise, it intends to announce a new trend in this same direction but carried out by another actor. Reference is made to the modality by which a part of the citizenry assumes, by its own means, the rearrangement of the urban space through the installation of physical barriers to avoid or impede the presence of this population in the surroundings of their properties. This action would allow observing the situation that certain social groups go through in an increasingly exclusive city.

\section{Resumo}

Este artigo pretende adentrar-se em algumas das possíveis consequências que traz aparelhada a implementação de políticas de tipo neoliberal no espaço público, especificamente na cidade de Buenos Aires. O artigo centra-se na caracterização da noção de cidade neoliberal, para posteriormente aprofundar nas formas que assume a espacialidade neoliberal em dita cidade através do caso dos moradores de rua, é dizer, pessoas e famílias que habitam cotidianamente no espaço público. Para desenvolver o pretendido, o artigo versará nas formas plas quais esta população vê-se expulsada do espaço público tanto por ações indiretas quanto diretas por parte da administração da cidade. Igualmente, pretende dar a conhecer uma tendência nova, nesta mesma direção, mas levada a cabo por outro ator. Se faz referência à modalidade pela qual uma parte da cidadania, assume, por seus próprios meios, o reordenamento do espaço urbano através da instalação de barreiras físicas para evitar ou obstaculizar a presença desta população nos redores de suas propriedades. 
Este acionar permitia observar a situação que atravessam alguns grupos sociais em uma cidade cada vez mais excludente.

\section{Introducción}

A principios del siglo XXI, según Carrión (2001), se estaba atravesando una nueva coyuntura urbana. Entre los cambios centrales identificados da cuenta que a escala mundial se estaba viviendo un fenómeno de globalización social, cultural y económica que concentraba sus efectos en lo local. Además, detectaba un proceso de reforma del Estado y de impulso a la apertura económica. Todo esto acompañado con una revolución científico-tecnológica que introducía transformaciones notables en la aproximación relativa de los territorios distantes, lo que generó una modificación en la geografía planetaria. Un cambio de esta magnitud, sostenía, creaba el escenario para la gestación de una nueva forma de ciudad. Siguiendo esta visión, para Herzer y Rodríguez (2000), hacia principios del siglo los cambios producidos en la tecnología de la información y en las telecomunicaciones, sumados a los procesos de globalización, provocaron la caducidad de las representaciones clásicas de ciudad. En este sentido, Carrión (2001) identificaba el surgimiento de nuevos conceptos que tenían por objetivo explicar las nuevas realidades urbanas. Menciona el concepto de 'ciudad informacional' de Castells (1997) y el de 'ciudad global' de Sassen (1999) como terminologías que permitían dar cuenta del pasaje de una ciudad que deja su espacio “enclaustrado en fronteras" a otra que se organiza a partir de la articulación en un sistema o red. Esta breve introducción da cuenta que lo definido por ciudad o por urbano se modifica constantemente, en especial a partir de los cambios devenidos del contexto social, económico y político. De este modo, se podría afirmar que lo comprendido por ciudad se "encuentra en permanente construcción-reconstrucción, porque nunca se acaba; se trata de un 'producto social' en proceso de cambio constante que tiene historia" (Carrión, 2001, p. 7).

En esta línea, tomando como referencia el análisis de ciertos procesos y fenómenos observados en las urbes contemporáneas, se plantea la propuesta de precisar ciertas formas que asume la cuestión urbana hoy. De este modo, desde varios enfoques, grupos de investigación y seminarios en toda latinoamericana se detectan iniciativas que dan cuenta de las transformaciones acontecidas en los últimos tiempos por medio del empleo de la noción de 'ciudad neoliberal'. Este artículo pretende introducir las particularidades que asume esta noción y las modalidades que adopta la espacialidad neoliberal por medio del análisis de la expulsión a la que se ven expuestos uno de los grupos sociales más vulnerables en la Ciudad de Buenos Aires; se hace referencia al grupo denominado como 'habitantes de la calle"
${ }^{1}$ Este es un fenómeno dificil de dimensionar por las propias caracteristicas de la población en cuestión, como son la permanente circulación, la intención de pasar desapercibidas, el ingreso y egreso constante de instituciones, entre otros. En este sentido, es que esta problemática es abordada generalmente desde una metodología de tipo cualitativo; esta brinda un gran aporte desde su perspectiva de análisis, "sin embargo, cualquier fenómeno de esta envergadura debe - necesita- ser cuantificado para poder tomar medidas al respecto, pero aqui radica la dificultad a la hora de analizar las formas de relevamiento y abordajes y actores involucrados" (Rosa, 2013, p. 563). Recientemente, se conocen los datos arrojados por el último relevamiento desarrollado por el Gobierno de la Ciudad. Según este, realizado en abril del 2017 , en la actualidad habitan en las calles de la ciudad 1066 personas. En este caso, se reconoce el aumento de la población residente en el espacio público en un 23,1\% con respecto al año anterior. Por su parte, diferentes organizaciones sociales que trabajan habitualmente con esta problemática lanzaron en el mayo del 2017 un relevamiento propio de-

territarios 39

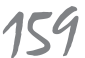




\section{$\Leftarrow$}

nominado Censo popular. Este señala que en la ciudad viven en situación de calle 5872 personas, de las cuales 823 son niños, $y$, además, señala que más de 20000 personas habitan en situaciones de vulnerabilidad habitacional al punto que los colocan como personas y/o familias en riesgo inminente de llegar a habitar en las calles en el corto plazo si no se implementan acciones y politicas eficientes. Esto se resalta dado que el origen del aumento y complejización de la problemática se localiza tanto en cuestiones de tipo económicas como el trabajo informal o el desempleo, pero también por dificultades en el acceso a la vivienda de personas y familias de menor ingreso en la ciudad. Para la obtención de precisiones metodológicas generales sobre la temática consultar Rosa (2013).

\section{territarias 39}

Con esta categoría se delimita a varones y mujeres adultos - con o sin niño/as- que habitan en las calles, veredas y plazas de la ciudad. Asimismo, se incluye a las personas y familias que asisten a paradores nocturnos y hogares de tránsito del Gobierno de la Ciudad de Buenos Aires, como a los que concurren a los hogares, comedores, duchas y ollas de las Organizaciones de la Sociedad Civil y que habitan en el espacio urbano (Rosa, 2012). La expulsión a la que se hace referencia es la que ocurre por medio del accionar de la administración de la ciudad como también por una parte de la ciudadanía residente en la ciudad. Esta última, resulta una práctica urbana relativamente reciente.

El proceso de investigación que se requirió para la realización de este artículo se basó en el trabajo desarrollado por la autora para la elaboración de su tesis doctoral. Esta fue una investigación de tipo cualitativa que incluyó observaciones participantes y entrevistas a la población en cuestión alojada en instituciones o bien que habitaban en el espacio público. Cabe aclarar que lo planteado en este artículo forma parte de análisis posteriores realizados a partir de la observación de nuevos procesos y prácticas urbanas que involucran a este grupo social en un contexto de creciente implementación de políticas de tipo neoliberal en el espacio urbano. Se entiende que serían políticas y acciones que buscan desplazar de los espacios públicos a las poblaciones consideradas como 'indeseables', mediante un accionar disuasorio $\mathrm{y} / \mathrm{o}$ violento, para intentar alcanzar espacios públicos limpios, seguros, controlados y cercanos a los sentidos estéticos que poseen los sectores de mayores ingresos. Esto traería como consecuencia un proceso de vigilancia constante de estos ámbitos y la creciente expulsión de determinados los grupos sociales.

Este tipo de políticas se desarrolla en el marco de la constitución de una 'ciudad neoliberal'. El uso de dicha noción se vincula con el reconocimiento de las especificidades que asume la ciudad en la actual coyuntura urbana. De este modo, se utiliza esta terminología para señalar la forma particular de funcionamiento que posee la ciudad "bajo las condiciones concretas del capitalismo en su fase actual" (Ornela, 2000 , p. 58). Asimismo, esta terminología permite hacer hincapié en los efectos que esta forma de ciudad tiene en el espacio urbano como en la vida cotidiana de las personas. Específicamente, interesa hacer referencia a los impactos negativos que el neoliberalismo genera en los grupos más vulnerables de la sociedad. Teniendo este punto de partida, se realizará a continuación una pequeña introducción a la conceptualización de la noción de 'ciudad neoliberal'. Posteriormente, se adentrará en las características que asume el espacio público en este tipo de ciudades, para luego introducir el análisis propuesto en relación con las formas de expulsión directa como indirecta que afectan, en especial, a los habitantes de la calle. Por último, a partir de lo planteado, se hará una reflexión final como cierre del artículo. 


\section{Ciudad neoliberal}

Desde mediados de la década de 1970 se inaugura un nuevo escenario político y económico en el ámbito mundial. En ese momento, Gran Bretaña y Estados Unidos adoptaron una nueva política económica denominada neoliberalismo. Esta fue implementada a partir de discursos, programas e instituciones provenientes del campo académico y político que sentaron las bases para instalar lo que se denominó como pensamiento "único". De este modo, se presentaron las premisas neoliberales como una suerte de destino inevitable (Bologna, 2002). Específicamente, esta corriente se caracteriza por considerar que "el bienestar humano puede ser logrado mejor mediante la maximización de las libertades empresariales dentro de un marco institucional caracterizado por derechos de propiedad privada, libertad individual, mercados sin trabas, y libre comercio" (Harvey, 2008, p. 1). Esta reestructuración condujo al abandono de las políticas intervencionistas que hasta el momento habían sido implementadas en el marco del denominado Estado de Bienestar. Según De Mattos (2016), la implementación de esta nueva política implicó la transición entre "una dinámica económica estructurada en torno al sector industrial hacia otra en que ese papel pasó a ser cumplido por el sector financiero" (2016, p. 32). Este proceso, siguiendo al autor, generó un excedente de capital que alcanzó una magnitud inconmensurablemente superior a la lograda en cualquier fase anterior del desarrollo capitalista. Por esa razón, el capital requería de nuevos destinos - tanto geográficos como sectoriales- que pudiesen ofrecer condiciones para su valorización. Dentro de esta búsqueda, los negocios inmobiliarios se situaron como una de las alternativas más pertinentes. De este modo, los flujos de inversión se dirigieron preferentemente, y en su mayoría, hacia los grandes espacios urbanos (Ciccolella, 2014) al punto de que las regiones urbanas, en los últimos años, se tornaron posiblemente en el ámbito de mayor acumulación de capital (Borja, 2016) y, en conjunto, en parte central del funcionamiento del sistema económico (Rodríguez, 2009).

Las ciudades, con el fin de mejorar su capacidad de captación de los flujos de inversión, por medio de nuevas políticas y normativas, reorganizaron su espacio físico y su estructura. Los nuevos tiempos trajeron modificaciones en la gestión urbana, específicamente en dos puntos: "la ciudad es concebida como una entidad competitiva inmersa en un espacio global de competición [y] el mercado y las mentalidades competitivas son promovidos a través de nuevas prácticas en la gestión pública" (Schipper, 2011 citado en Díaz, 2013 , p. 3). La competitividad y el crecimiento fueron aspectos que se tornaron relevantes para reacondicionar la ciudad. Esto implicó la implementación del:

[...] marketing urbano orientado a la venta internacional de las ciudades ${ }^{2}$, la expansión de las formas de gestión privado-pública en la ciudad, el desarrollo de los megaproyectos
2 Particularmente, "las ciudades que participan en este juego buscan tener la mayor cantidad de iconos que las representen, tanto en el ámbito nacional como internacional, de manera instantánea. La finalidad es transformar el denominativo de la ciudad en algo más que en un nombre; la idea es transformarlo en una marca. Que la sola mención de esos nombres (Nueva York, Barcelona, Rio de Janeiro...) dispare de inmediato una serie de asociaciones, imágenes y hasta sensaciones que, eso sí, buscarán siempre ser positivas" (Latorre, 2004, s/p).

territarias 39

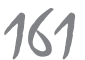


3 Parques, plazas, veredas, áreas verdes como reservas naturales, etc.

${ }^{4}$ Como la luz, el agua, la recolección de basura, la seguridad, el transporte, el alumbrado público, etc.

\section{territarias 39}

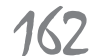

urbanos y el esfuerzo por dejar al margen del debate ciudadano los contenidos de las políticas urbanas (Díaz, 2013, p. 4).

Desde la década de 1980, con la instalación de una nueva política urbana y la consolidación de un régimen de acumulación conducido por las finanzas (De Mattos, 2016), se desarrolló el marco formal para la institucionalización de la 'ciudad neoliberal' (Abramo, 2012). Según Theodore et al. (2009), "durante las tres últimas décadas, las ciudades se han convertido en espacios cada vez más centrales para la reproducción, transmutación y continua reconstitución del neoliberalismo mismo" (2009, p. 10). Para estos autores las ciudades se han tornado en terrenos de prueba para la experimentación de políticas neoliberales. Por ello, señalan, que estas son incubadoras para la reproducción del neoliberalismo como régimen institucional viviente. De este modo, siguiendo a Janoshchka (2011), se concibe que el neoliberalismo ha introducido enormes cambios en las condiciones generales de la política urbana y en los modos de imaginar, percibir, diseñar y gestionar las ciudades pues:

un aspecto central de la política urbana en la era neo-liberal son las nuevas reglas, regulaciones, programas y micro-políticas que, siempre desde una perspectiva económica, ponen la ciudad en valor. La consecuencia de esa gestión es una reorganización de la política urbana según los principios y las dinámicas de la administración privada y capitalista (Sequera \& Janoshchka 2012, p. 517).
Esto implica, como señala Castells (1979), que "el Estado concentra sus inversiones en aquellas funciones urbanas necesarias al funcionamiento del polo dominante, o sea el capital. Mientras que se dejan de lado las necesidades de vivienda, transporte y equipamiento social de la población" (citado en Ornelas, 2000, p. 54). Como se observa, en un escenario neoliberal, se amplía el protagonismo y la participación de los capitales privados frente a otros. En este sentido, lo considerado como público — sean empresas, grandes áreas urbanas, espacios públicos ${ }^{3}$, servi$\operatorname{cios}^{4}$, etc. - tiende a ser privatizado pues se privilegia la perspectiva, la lógica y los intereses de los grandes capitales privados.

Si bien, por lo descrito es posible dar cuenta de los rasgos en común que posee la política económica neoliberal, los alcances de estas son diferentes según la ciudad en el cual se apliquen. Específicamente, en cada país se detectan aspectos híbridos al combinarse variados elementos culturales, sociales, políticos, económicos y temporales que conviven junto a la propagación de lógicas neoliberales. En este sentido, hay autores que hacen referencia a la noción del "neoliberalismo realmente existente" para diferenciarse de los preceptos teóricos universalistas. Theodore et al. (2009) señalan que esta denominación destaca la inserción contextual de los proyectos de reestructuración neoliberal. De este modo, se sostiene que:

el neoliberalismo se instala en cada lugar no con una estructura rígida sino tomando 
elementos propios que en cada lugar lo definen; no como un conjunto fijo de atributos sino como una lógica de gobierno cambiante que es tomada de modo diferente en cada contexto político (Ong, 2007, en Blanco \& Macagno, 2014, p. 102).

Esto conduce a que ni siquiera al término neoliberalismo le corresponda un significado único en los diferentes países (Grimson, 2007).

Más allá de los particularismos, que requieren ser reconocidos, resulta innegable que el neoliberalismo ha permeado con fuerza en las políticas públicas urbanas, lo que ha generado transformaciones y reestructuraciones institucionales dominadas por las fuerzas del mercado (Janoshchka, 2011). En este sentido, el uso de la noción de 'ciudad neoliberal' se vincula con el reconocimiento de las especificidades que asume la ciudad en el periodo histórico actual. De este modo, se podría sostener que se utiliza esta terminología para dar cuenta de:

cómo funciona la ciudad bajo las condiciones concretas del capitalismo en su fase actual de globalización y neoliberalismo. Es en estos términos históricos que hablamos de ciudad neoliberal, no porque el neoliberalismo haya inventado lo urbano y su compleja problemática, sino para comprender y explicar adecuadamente lo que cambia en la ciudad y en la gestión urbana bajo este modelo (Ornela, 2000, p. 58).
Es posible pensar que esta noción permite identificar, caracterizar y analizar la consolidación de ciertos fenómenos urbanos iniciados en décadas anteriores. En este sentido, se considera que el uso de esta terminología permite hacer hincapié en los efectos que esta forma de hacer ciudad tiene en la configuración urbana y en la vida cotidiana de los ciudadanos. Concretamente, siguiendo a Ornela (2000), se hace referencia a los impactos negativos que el neoliberalismo ocasiona en los grupos más vulnerables de la sociedad. Por ello, introducir la noción de 'ciudad neoliberal' implica acercarse también a las problemáticas urbanas como segregación, desigualdad, pobreza, estigmatización, gentrificación, entre otras. Esto se debe a que "el neoliberalismo ha sido incapaz de enfrentar los efectos más negativos de la ciudad capitalista, incluso, en muchos casos, los ha profundizado" (Ornela, 2000, p. 62). Para Ramírez (2008), las ciudades neoliberales pueden ser definidas "como aquellas que están divididas entre las élites financieras y la gran masa de trabajadores de servicios con salarios bajos mezclándose con los marginados y los desempleados" (p. 128). La autora, siguiendo a Harvey (2005), señala que, a diferencia de otras denominaciones, la de 'ciudad neoliberal' posee un carácter político, pues da cuenta de "las evidencias y consecuencias políticas de los cambios sufridos en la obtención y organización de la plusvalía en el momento neoliberal" (p. 127). 


\section{El espacio público en la 'ciudad neoliberal'}

La implementación de políticas desde una lógica neoliberal ha generado transformaciones profundas en la gestión urbana y en la organización espacial. En este sentido, Álvarez (2013) señala que una de las consecuencias del neoliberalismo que afecta significativamente a las ciudades es la privatización del espacio público, pues el capital privado pasa a hacerse cargo del espacio público tornándolo en propiedad privada a pesar de estar abierto al uso de todos los ciudadanos. Para Monreal (2016), una de las características de las ciudades neoliberales "es el aceleramiento de los procesos de privatización y mercantilización del espacio público y su conversión en un ámbito cada vez más residual” (p. 99). Para esta autora, el espacio público en este tipo de ciudades adopta un doble carácter: por un lado, la movilización del espacio tiene fines económicos como es la búsqueda de beneficios y de acumulación y, por otro, es un "ámbito de intervención técnica, de legitimación y creación del consenso que encubre desigualdades, las múltiples desigualdades sociales" (2016, p. 102).

Según Bachiller (2009), el proceso por medio del que la lógica privada avanza sobre la pública en los espacios públicos se puede observar a partir de la proliferación de los grandes centros comerciales, el cierre de los baños públicos, la conformación de espacios públicos en los cuales el acceso se encuentra limitado a quienes poseen una cierta capacidad de consumo, entre otros.
Asimismo, señala la existencia de espacios abiertos que simulan ser públicos, pero están regidos por normas estrictas y por la presencia de custodios privados. García (2005) señala que todos los tipos de privatización del espacio público poseen la característica de poner trabas al libre acceso al espacio público y, además, evidencian la permisividad de la gestión municipal para llevar a cabo estas acciones.

Estas acciones sobre el espacio público conducen a revisar la propia conceptualización que se tiene sobre este espacio. Muchos debates se han dado en torno a las funciones que posee o debería tener el espacio público. Hay perspectivas que lo consideran un espacio de anonimato $\mathrm{y}$ heterogeneidad frente a otras posturas más idealizadas en las cuales se "presupone que los habitantes pueden acceder y utilizar equitativamente todos los espacios y lugares a pesar de una diversidad social y diferencias en su estatus socioeconómico, sociogeográfico y sociocultural" (Motta et al., 2013, p. 53). Otras miradas cuestionan esta última argumentación dado que sostienen que desconoce la existencia de variadas posibilidades de acceso y uso de este espacio, lo cual reflejaría las correlaciones de fuerzas (Oslender, 2000) existentes entre diferentes sectores sociales y sus intereses. En este sentido, se piensa en sectores y usos más legítimos que otros del espacio público.

Esto último se evidenciaría particularmente en el caso de los denominados como habitantes de la calle, es decir, personas de ambos sexos, ancianos/as y familias que 
habitan en la calle dado que "no pueden permitirse prescindir del espacio público" (Borja, 1998, p. 13). Esta designación es utilizada, pues se entiende que un rasgo central de esta problemática social es el medio en donde las personas habitan y desarrollan su vida cotidiana ${ }^{5}$. Esta vida "al aire libre" en muchos casos "desentona" con el paisaje urbano que se pretendería en la ciudad desde el urbanismo neoliberal, es decir, limpio, seguro, armónico, bello y saludable. Esta pretensión se vincula con los objetivos de la espacialidad neoliberal que busca la proliferación de una estética aséptica (Sequera \& Janoshchka, 2012). Esto se relacionaría con la ambición de lograr una ciudad atractiva para los sectores de mayores ingresos, turistas e inversores. Para lograrlo, en diferentes ciudades del planeta, se implementan acciones que tienen como objetivo expulsar a los "indeseables" del espacio público, pues estos se tornarían más visibles al habitar en los espacios públicos de las áreas centrales de la ciudad.

Específicamente en esta dirección, es posible señalar diversas acciones llevadas a cabo por la anterior y actual gestión a cargo de la administración de la Ciudad de Buenos Aires. Primeramente, se puede identificar la expulsión indirecta de esta población por medio de la incorporación de cerramientos en plazas, parques y monumentos, como así también con la instalación cámaras de vigilancia y contratación de personal de seguridad privada para controlar los espacios públicos. Este accionar, ampliamente diseminado en las diferentes comunas de la ciudad, se relaciona con discursos que se vinculan a los problemas de inseguridad que afectan a estos espacios por la posibilidad de sufrir un robo, el uso indebido que hacen de estos espacios los jóvenes que se alcoholizan por las noches y también por la falta de cuidado por parte de la población del equipamiento allí localizado (mesas, sillas, juegos de niños, monumentos, aparatos para realizar actividad física, plantas, entre otros). Estas medidas pueden ser vinculadas a lo que Bachiller (2009), siguiendo a Davis (2001), señala como reformas urbanas de alcance 'micro'. Esto sería la utilización de una serie de elementos, en apariencia, decorativos que tienen como finalidad constituirse en barreras que dificultan el uso de los espacios públicos. Entre estos elementos menciona las rejas y vallas que obstaculizan, específicamente a los habitantes de la calle, la posibilidad de tomar asiento o dormir o protegerse de la lluvia, también señala la existencia de tachos de basura diseñados para que no se pueda introducir con facilidad un brazo, los bancos de las plazas y paradas de subte y colectivo que dificultan que una persona pueda acostarse allí, entre otros. Además, de estas barreras se puede reconocer la instalación, por parte de la administración de la ciudad, de grandes maceteros en esquinas o calles para evitar la localización tanto de los habitantes de la calle, como de vendedores ambulantes y/o los denominados 'manteros' que son personas que venden productos de diferente tipo localizados sobre una manta en el piso de calle y veredas ${ }^{6}$.
${ }^{5}$ Esta población se localiza en diferentes barrios de la ciudad de Buenos Aires, es decir, que es posible hallarla en áreas de mayor poder adquisitivo como también en barrios de menores ingresos. Asimismo, hay zonas como el centro cívico de la ciudad y áreas cercanas a estaciones de transporte (tren, ómnibus) en donde se localizan las denominadas "ranchadas", es decir, grupos de habitantes de la calle que co-babitan un espacio público de manera permanente. También es posible localizar personas solas de ambos sexos - mayormente varones, pero en los ultimos tiempos se ha extendido también a mujeres solas-que habitan en zonas cercanas a las instituciones tanto públicas como privadas que les brindan diferentes tipos de asistencia, pero también en esquinas y veredas de diferentes barrios de la ciudad.

${ }^{6}$ Estos son denunciados por comerciantes de la zona y son ellos los que solicitaron al gobierno de la ciudad la colocación de estas barreras que impidieran su instalación.

territarias 39

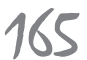


Sumado a lo anterior, se desarrollarían también acciones de expulsión directas de las personas y familias que habitan el espacio público de la ciudad. Las modalidades para llevarlo a cabo son diversas. En muchos casos son violentados por las fuerzas de seguridad quienes los expulsan, les arrojan sus pertenencias, los golpean, agreden verbalmente, amenazan con quitarles a sus hijos, intimidan por medio de fotografías, etc. como también son ahuyentados con agua como parte de las tareas desarrolladas por el área de higiene urbana de la ciudad. Los habitantes de la calle son mojados por las mañanas para que desalojen la vereda en la que están durmiendo antes de que comience el día laboral. Se podría decir que se intenta que sean "invisibles" a la luz del día, en especial en ciertas áreas de la ciudad, ya que en otros barrios esta población se concentra a diario - en especial en las áreas aledañas a comedores, paradores, hogares, iglesias - sin generar la necesidad de desarrollar las mismas acciones. Estas prácticas se profundizan ante ciertos eventos como la conmemoración de alguna fecha o el desarrollo de un acto de trascendencia pública como fue la visita del presidente de los Estados Unidos a la Argentina en el mes de marzo del año 2016.

Posiblemente la intencionalidad de limpiar y ordenar el espacio público condujo a que se cree, en el año 2008, en el ámbito del Ministerio de Ambiente y Espacio Público, una Unidad de Control del Espacio Urbano (UCEP). Las funciones de esta unidad se vinculaban con mantener territarios 39 166 colaborar en su orden y asistir operativamente en el confisco de elementos, materiales y mercaderías acopiadas en el espacio público. Para "restaurar el espacio público", como era definido su accionar por este organismo, expulsaban de los espacios públicos a los 'indigentes'. Esta unidad estaba constituida por un grupo de personas que por las noches eran los encargados de desplazar a esta población. Su operatoria era relevada en planillas en las cuales se registraban cuántos eran expulsados por día de la vía pública sin otra justificación que el hecho de habitar en esos lugares. Durante los operativos se les extraían o tiraban sus pertenencias, lo cual resultaba muy grave para los habitantes de la calle, pues estas son centrales en la vida en la intemperie (ropa, frazadas, cacerolas, colchones, etc.) y, al mismo tiempo, son difíciles de reponer de nuevo. También en estos operativos los documentos de identidad eran sustraídos o bien extraviados, lo que generaba un problema adicional a su vida diaria. Este organismo fue denunciado por la defensoría del pueblo, partidos políticos, organizaciones de derechos humanos, periodistas y por habitantes de la calle que habían sido golpeados y maltratados por su personal. A raíz de estas denuncias y el conocimiento generalizado de su accionar, en el año 2009, la UCEP fue disuelta. Sin embargo, en la actualidad, las expulsiones con modalidades semejantes, según diversos relatos y denuncias, continúan.

Junto a estas acciones de expulsión a cargo de la administración de la ciudad, es posible dar cuenta de novedosas 
modalidades de expulsión —-denominadas como indirectas - a cargo de una parte de la ciudadanía que reside en zonas de medio $\mathrm{y}$ alto poder adquisitivo. Estos ciudadanos intentan, por sus propios medios, evitar, o bien obstaculizar, que los habitantes de la calle se localicen o habiten en sus entradas de edificios, sus veredas o vidrieras de locales. Con esta finalidad colocan rejas de diferente tipo y tamaño (dependiendo del área que se intenta resguardar) y también diversidad de macetas y plantas para impedir que los habitantes de la calle pueden dejar sus pertenencias o bien residir en esos espacios. Algunas de las razones por las cuales se lleva a cabo este accionar se vinculan con la falta de higiene de esta población y sus pertenencias, la acumulación de basura que generan, la realización de sus prácticas cotidianas en ámbitos públicos y de manera visible (preparar los alimentos, higienizarse, tener relaciones sexuales, etc.), el aumento de la peligrosidad en la zona por la posible atracción de delincuencia, entre otras. Este accionar ciudadano es posible vincularlo con lo que analiza Da Matta (1997, 2002), quien sostiene que la entrada a la propia casa, la vereda y hasta la calle en donde esta se ubica pueden ser consideradas como más propios que el resto de los lugares públicos. De este modo, estos espacios se constituirían en una prolongación de la propia casa, por lo cual son vivenciados como un ámbito especial que debe ser de algún modo protegido y restringido. En este sentido, el hecho de que esta población habite los lugares considerados como más propios y cercanos, podría ser experimentado como una intrusión (Bachiller, 2009). A este accionar se suma el caso de los propietarios de locales que, como una prolongación de su negocio, instalan en el espacio público vallas, maceteros, pasamanos, publicidad y/o sombrillas que limitan la circulación de las personas y reconfiguran el espacio público. Asimismo, instalan vidrios y canteros con plantas en las veredas con el fin de mejorar la visual del paisaje urbano y para evitar las posibles intromisiones - venta ambulante, mendicidad, etc.- que afecten a los clientes. Estas prácticas, que pueden ser entendidas como una apropiación cívica (Gómez, 2014), podrían dar cuenta de una tendencia que lleva al privilegio de la lógica privada y comercial de estos ámbitos, ya que se priorizaría el acceso y la permanencia de la población que posee el poder adquisitivo para hacerlo; asimismo, limitan u obstaculizan la circulación y accesibilidad de los transeúntes en general como también, y especialmente, el acceso a personas consideradas como "indeseables". También se podría agregar que este tipo de acciones genera cambios en la fisonomía de la ciudad y de los espacios públicos sin haber atravesado procesos de consenso y/o adecuación a las normativas urbanas. En definitiva, a partir de las apropiaciones que realizan sobre las áreas públicas logran beneficios económicos y también físicos (Gómez, 2014).

Estas prácticas cívicas podrían dar cuenta de la legitimidad que posee, en términos generales, la expulsión de esta población en ciertas áreas de la ciudad. territarias 39

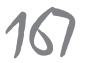


Como así también el aval con la que cuenta la administración de la ciudad para aumentar la seguridad y vigilancia de los espacios públicos con el fin de evitar el acceso o la permanencia de los grupos asociados con la delincuencia, el peligro y la suciedad. Como señala García (2005) "la opción del cerramiento no solo surge de la decisión municipal, sino que también está ampliamente aceptada por un amplio sector de la población que la demanda y que llega a ejecutarla físicamente" (p. 210). De este modo, resulta un accionar $\mathrm{y}$ un discurso legitimado por cierta parte de la ciudadanía, al punto, podría decirse, que es imitado. De este modo, se puede observar que las acciones desplegadas por la administración de la ciudad sobre el espacio público "producen sentido en torno a usos y usuarios legítimos del mismo" (Martell \& González, 2013, p. 6). Se desarrollan "discursos performativos" sobre el desorden urbano centrados en la idea de la existencia de "clases peligrosas" lo que permite la ejecución de políticas de seguridad y la introducción de nuevas formas discriminatorias de vigilancia y control social (Theodore et al., 2009, p. 9).

Como se señaló previamente en torno a la privatización de los espacios públicos, también la denominada gobernanza de la seguridad, siguiendo a Janoshchka (2011), puede ser caracterizada como una de las políticas transversales de la era neoliberal. Esta implica la implementación de diferentes dispositivos de vigilancia, el re-diseño de espacios urbanos y la organización del control social en los cuales participan tanto las administraciones públicas como muchas empresas privadas. En este sentido, según el autor, transformar el espacio urbano en la era neoliberal consiste en incluir en el discurso el tema de la inseguridad, pues la sospecha resulta funcional para implementar medidas de vigilancia y control que transforman los modos de la convivencia, reordenando el espacio urbano y gestando nuevos espacios de esparcimiento y recreación vinculados, generalmente, al consumo en ámbitos seguros y protegidos. En este sentido, la reconfiguración urbana neoliberal se dirige a comercializar el espacio público a partir del establecimiento de ciertas estrategias y condiciones que impulsan "un uso hedonista y comercial frente a otros posibles" (Sequera, 2014, p. 69). Este tipo de formas traen aparejadas el desarrollo de una vida cada vez más restringida ya que "las relaciones de sociabilidad quedan condicionadas por el tipo de acceso y de uso que se den en estas plazas y calles, y por la delimitación de estos encuentros sociales cada vez más a lugares privados o privatizados" (Sequera \& Janoshchka, 2012, p. 517). De este modo, es posible pensar que:

el neoliberalismo incidió (e incide) en los modos en que el mundo es narrado, en los sentidos adjudicados al pasado y al futuro, en las características de los proyectos intelectuales, las prácticas de la vida cotidiana, la percepción y el uso del espacio, los modos de identificación y acción política (Grimson, 2007, p. 11). tersitarios 39 
Por lo descripto, podría sostenerse que el neoliberalismo y sus lógicas han logrado penetrar de algún modo en todas las esferas de la vida social —además de la económica- pues logra formar parte de la subjetividad, al punto de naturalizarse y de reproducirse continuamente.

\section{Reflexiones finales}

El accionar sobre el espacio público impulsado por la administración de la Ciudad de Buenos Aires se visualiza por medio de la reorganización de los espacios, un mayor control y vigilancia, la instalación de cámaras de seguridad, la mayor cantidad de personal de vigilancia privada, la colocación de rejas en plazas, monumentos, parques, etc., como también por medio de la expulsión sistemática de las personas que habitan en estos espacios y la instalación de obstáculos para su vida cotidiana. Sumado a lo anterior, se observan acciones desplegadas por parte de la ciudadanía, en ciertos ámbitos de la ciudad, que tienden también a la reorganización del espacio público, como es la instalación de rejas y maceteros en sus domicilios o cercanías, y por medio de la colocación de vallas, publicidad, vidrios, mesas y/o sombrillas en diferentes comercios. Estas acciones asumidas por la ciudadanía con la intención de apartar de estos espacios a los "indeseables" son entendidas como expresiones que legitiman el accionar del gobierno y, además, dan cuenta de la percepción de la existencia de un uso del espacio público más avalado que otro, pues se podría afirmar que el accionar vecinal tiene entre sus intenciones lograr mayor control, vigilancia y limpieza de estos ámbitos.

La relación entre el espacio público y los procesos de exclusión tanto directa como indirecta hacia los habitantes de calle es entendida, en este artículo, como gestada mediante de un proceso influenciado por las lógicas y los sentidos que asume en la actualidad la 'ciudad neoliberal'. De este modo, las prácticas de expulsión cristalizan las tensiones que existen sobre el uso y apropiación de lo público en la ciudad actual pues el "espacio público no es neutral, es un escenario de conflictos y negociaciones sociales a diversas escalas que lo redefinen continuamente" (Portal, 2009, p. 63). En este sentido, es que las acciones a las cuales se ven expuestas los habitantes de la calle permiten, de algún modo, acercarse a las características que asume la vida urbana en la actualidad y evidenciar cómo se concibe la ciudad y cuáles son los modos posibles de ser habitante urbano (Rosa, 2012).

Las poblaciones más vulnerables en su experiencia urbana diaria deben atravesar diversas barreras físicas, como fueron mencionadas, pero también barreras de tipo simbólico. Las vivencias atravesadas por esta población pueden conllevar profundos impactos en la subjetividad al ser expulsados, temidos, rechazados y estigmatizados por sus comportamientos y/o por su aspecto físico ${ }^{7}$. Esto, puede considerarse como una consecuencia - muchas veces imperceptible - de la implementación de políticas de corte neoliberal en los
7 Situaciones que se suman a las dificultades cotidianas que atraviesan estas personas al no tener un lugar propio para dormir, comer, higienizarse, vestirse, etc. En muchos casos, deben resolver estas cuestiones diariamente y articulando diversidad de estrategias $y$ actores. territarios 39

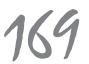


espacios urbanos. En este sentido, interesa señalar que estas modalidades incrementan la desconfianza hacia el "otro" diferente, potenciando la discriminación hacia ciertos grupos sociales. La búsqueda de un espacio público limpio, armónico y seguro, según se pudo dar cuenta, implica desplegar acciones que restringen la presencia de ciertas poblaciones, especialmente las que encuentran en estos ámbitos un lugar en donde habitar, pues la calle es el lugar donde se hace visible lo que intenta ser invisibilizado (Delgado, 2007). Esto resulta relevante dado que, a partir de las prácticas efectuadas y los sentidos que le otorgan al espacio público los habitantes de la calle, realizan un proceso de apropiación del espacio en el que habitan (Rosa, 2012). En este proceso de apropiación "los grupos sociales hacen suyo el espacio significándolo $[\ldots]$, se le otorga sentido al espacio y se generan elementos que favorecen la identificación y la pertenencia” (Portal, 2009, p. 64).

Estas prácticas podrían cristalizar la consolidación y profundización de ciertas tendencias propias de la ciudad capitalista que el modelo neoliberal no supo desarticular, sino que, por el contrario, ha profundizado. Desde esta visión es que se introduce la noción de 'ciudad neoliberal' en la cual se observa la consolidación de ciertas problemáticas urbanas vinculadas al aumento de las desigualdades y la exclusión. Cuestiones propias de la actualidad de la Ciudad de Buenos Aires pero que también son compartidas por otras grandes ciudades latinoamericanas de principios del siglo XXI.

\section{Referencias}

Abramo, P. (mayo de 2012). La ciudad comfusa: mercado y producción de la estructura urbana en las grandes metrópolis latinoamericanas. EURE, 38(114), 3569. doi: http://dx.doi.org/10.4067/ S0250-71612012000200002

Álvarez, L. N. (diciembre de 2013). El espacio público neoliberal. La desaparición del espacio social. La ciudad viva. Recuperado de http://www.laciudadviva. org/blogs $/ \mathrm{p}=20126$

Bachiller, S. (2009). Significados del espacio público y exclusión de las personas sin hogar como un proceso de movilidad forzada. Revista Española de Investigaciones Sociológicas (Reis). (128), 125137. Recuperado de http://www.reis. cis.es/REIS/PDF/REIS_128_OCT_ DEC_2009_125_1371234884714406. pdf

Blanco, J., \& Macagno, A. (2014). Políticas neoliberales y condicionantes estructurales: Movilidad, transporte y dinámica urbana en la Región Metropolitana de Buenos Aires. En: M. Janoschka, \& R. Hidalgo (Coords.), La ciudad neoliberal. Gentrificación y exclusión en Santiago de Chile, Buenos Aires, Ciudad de México y Madrid (pp. 101-114). Chile: Universidad Católica de Chile.

Bologna, S. P. (2002). El porvenir de la equidad. Aportaciones para un giro ético en la filosofía política contemporánea. Santiago de Chile: LOM, Universidad Alberto Hurtado.

\section{territarias 39} 170 
Borja, J. (2016). La vivienda popular, de la marginación a la ciudadanía. Geograficando, 12(2), 1-16. Recuperado de http://www.geograficando.fahce.unlp. edu.ar/article/view/Geoe009

Borja, J. (septiembre de 1998). Ciudadanía y espacio público. Ambiente y Desarrollo, (7), 13-22. Recuperado de http:// www.pieb.org/espacios/archivos/doconline_ciudadania_y_espacio_publico. pdf

Carrión, F. (2001). Las nuevas tendencias de la urbanización en América Latina. En F. Carrión, (ed.), La ciudad construida. Urbanismo en América Latina (pp. 7-24). Quito: FLACSO.

Castells, M. (1997). La era de la información. Economia, sociedad y cultura. Madrid: Alianza Editorial.

Castells, M. (1979). Ciudad, democracia y socialismo. México: Siglo XXI editores.

Ciccolella, P. (2014). Metrópolis Latinoamericanas. Más allá de la globalización. Buenos Aires: Editorial Café de las Ciudades.

Da Matta, R. (1997). A Casa \& A Rua. Río de Janeiro: Rocco.

Da Matta, R. (2002). Carnavales, malandros $y$ héroes. Hacia una sociología del dilema brasileño. México: Fondo de Cultura Económica.

Davis, M. (2001). Control Urbano: la ecología del miedo. Barcelona: Virus Editorial.

Delgado, M. (2007). El espacio público asusta. Entrevista. Recuperado de https:// www.lavaca.org/notas/manuel-delgado-el-espacio-publico-asusta/
De Mattos, C. (mayo-agosto de 2016). Financiarización, valorización inmobiliaria del capital y mercantilización de la metamorfosis urbana. Sociologias, (42), 24-52. doi: http://dx.doi. org/10.1590/15174522-018004202

Díaz, O. F. (2013). Sociedad, espacio y crisis en la ciudad neoliberal. En J. Cucó Giner, Metamorfosis urbanas. Ciudades españolas en la dinámica global (pp. 81107). Barcelona: Icaria. Recuperado de https://defensoresddhh2015.files.wordpress.com/2015/11/sociedad-espacio-y-crisis-en-la-ciudad-neoliberal.pdf

García, G. A. (2005). Miedo y privatización de los espacios públicos: phacer o deshacer la ciudad? En O. Gutiérrez (Comp.) La Ciudad y el Miedo. VII Coloquio de Geografía Urbana (pp. 209 - 221). Barcelona: Universitat.

Gómez, G. S. (2014). La privatización del espacio público en el centro de la ciudad de Xalapa, Veracruz. (Tesis de Maestría. Universidad Veracruzana, Xalapa). Recuperado de http://cdigital.uv.mx/ bitstream/123456789/42580/2/GomezGomezSonia.pdf

Grimson, A. (2007). Introducción. En A. Grimson, Cultura y neoliberalismo. Consejo Latinoamericano de Ciencias Sociales (pp. 11-15). Ciudad de Buenos Aires: CLACSO.

Harvey, D. (abril de 2008). El neoliberalismo como destrucción creativa. Rebelión. Recuperado de http://www.rebelion. org/noticias/2008/4/65709.pdf

Harvey, D. (2005). La liberación de la Ciudad. Investigación y Diseño. Anuario territarias 39 
del Posgrado de la División de Ciencias $y$ Artes para el Diseño de la UAM-Xochimilco, (2), 11- 29.

Herzer, H., \& Rodríguez, C. (noviembre de $2000)$. Sociología y ciudad: los desafíos actuales. Ciencias Sociales. (44), 1-2.

Janoshchka, M. (2011). Geografías urbanas en la era del neoliberalismo. Una conceptualización de la resistencia local a través de la participación y la ciudadanía urbana. Investigaciones Geográficas, Boletín del Instituto de Geografía, UNAM, (76), 118-132. doi: http://dx.doi. org/10.14350/rig.29879

Latorre, L. (abril-junio, 2004). Marketing y Ciudad. Revista Teina, (4). Recuperado de http://www.revistateina.es/teina/ web/Teina4/dossierciudadymarketing. htm

Martell, D., \& González, R. C. (2013). La expulsión de lo indeseable. La Unidad de Control del Espacio Público y la racionalidad política de la gestión del espacio urbano bajo el macrismo. (Tesina de grado, Universidad de Buenos Aires, Ciudad de Buenos Aires) Recuperado de http://comunicacion.sociales.uba.ar/wp-content/ uploads/sites/16/2013/02/La_ Expulsi\%C3\%B3n_de_lo_Indeseablefinal.pdf

Monreal, P. (2016). Ciudades neoliberales: ¿el fin del espacio público? Una visión desde la Antropología urbana. QUADERNS-E, 21(1), 98-112. Recuperado de http://www.antropologia.cat/ quaderns-e-323
Motta, J. M., Rosa, P., \& García, A. (noviembre de 2013). Perspectivas y tensiones del espacio público: los habitantes de la calle en la ciudad autónoma de buenos aires. Cuaderno urbano Espacio, Cultura, Sociedad 15(15). Recuperado de http://www.scielo.org.ar/pdf/cuba/ v15n15/v15n15a03.pdf

Ong, A. (2007). Boundary crossings. Neoliberalism as a mobile technology. Transactions of the Institute of British Geographers, (32), 3-8.

Ornelas, D. J. (enero-marzo de 2000). La ciudad bajo el neoliberalismo. Papeles de población, CIEAP/UAEM, 6(23), 44-69. Recuperado de http://www. redalyc.org/pdf/112/11202303.pdf

Oslender, U. (2000). Espacializando resistencia: Perspectivas de 'espacio' y 'lugar' en las investigaciones de movimientos sociales. En E. Restrepo, \& M. V. Uribe. Antropologias Transeuntes (pp. 195226). Bogotá: Instituto Colombiano de Antropología e Historia. Recuperado de http://antropologiadeoutraforma.files. wordpress.com/2014/02/ulrich_oslender_perspectivas-de-espacio-y-lugaren-las-investigaciones-de-movimientossociales.pdf

Portal, M. A. (septiembre-diciembre de 2009). Las creencias en el asfalto. La sacralización como una forma de apropiación del espacio público en la ciudad de México. Cuadernos de Antropología Social, (30), 59-75. Recuperado de http://cache.oalib.com/cache?m $=$ E1B7F6BDFEC066EF59EFBF26FBElCF57.html 
Ramírez, V. B. R. (enero-junio de 2008). Las ciudades neoliberales: Categorías, método y política. Revista Geográfica Venezolana, 49(1), 123-130. Recuperado de http://www.redalyc.org/ pdf/3477/347730375009.pdf

Rodríguez, C. L. F. (2009). De los espacios de exclusión a la exclusión social y política en el contexto de las ciudades actuales. Congreso de Geógrafos de América Latina, (12), 1-14.

Rosa, P. (2012). "Ser" habitante de la Ciudad Autónoma de Buenos Aires (experiencias y procesos de una ciudad en transformación). Boletin Científico Sapiens Research, 2(1), 60-65. Recuperado de https://dialnet.unirioja.es/servlet/ articulo? codigo $=3841453$

Rosa, P. (2013). ¿Cuántos son, quiénes son los habitantes de la calle? Acercamientos a las cifras. Revista Trabajo y Sociedad Sociologia del trabajo - Estudios culturales - Narrativas sociológicas y literarias, (21), 563-577. Recuperado de www. unse.edu.ar/trabajoysociedad

Sassen, S. (1999). La ciudad global. Nueva York, Londres, Tokio. Buenos Aires: EUDEBA.

Schipper, S. (2011). Not the market has failed, but the state. The hegemony of urban neoliberalism in the casa of Frankfurt am Main during the crisis 2008-2010. Conference: The struggle to belong. Dealing with diversity in 21st century urban settings. (RC21, 2011, 26, Amsterdam). Annual RC21 Conference. Research Committee on Urban and Regional Development, 1-13.

Sequera, J., \& Janoshchka, M. (mayo-junio de 2012). Ciudadanía y espacio público en la era de la globalización neoliberal. ARBOR Ciencia, pensamiento y Cultura, (755), 515-527. doi: https://doi. org/10.3989/arbor.2012.755n3005

Sequera, J. (2014). Ciudad, espacio público y gubernamentalidad neoliberal. Revista Urban, (7), 69-82. Recuperado de http://www2.aq.upm.es/Departamentos/Urbanismo/institucional/ articulos-ns/ns07/ciudad-espacio-publico-y-gubernamentalidad-neoliberal/ Theodore, N., Peck, J., \& Brenner, N. (marzo de 2009). Urbanismo neoliberal: la ciudad y el imperio de los mercados. Temas Sociales, (66), 1-12. Recuperado de http://barcelonacomuns.pbworks. $\mathrm{com} / \mathrm{w} /$ file/fetch/64059073/2009_ Urbanismo_neoliberal_brenner-peck-. pdf territarios 39

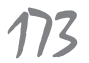


